Revista Eletrônica em Gestão, Educação e Tecnologia Ambiental Santa Maria, v. 20, n. 1, jan.-abr. 2016, p. 438-448

Revista do Centro de Ciências Naturais e Exatas - UFSM

ISSN : 22361170

\title{
Desenvolvendo e divulgando o conhecimento sobre plantas medicinais
}

\section{Developing and disseminating knowledge on medicinal plants}

\author{
Monik Compagnoni Martins ${ }^{1}$ e Tânea Maria Bisognin Garlet² \\ ${ }^{1}$ Acadêmica de Ciências Biológicas - Licenciatura Plena, Departamento de Zootecnia e Ciências Biológicas, Universidade \\ Federal de Santa Maria, Palmeira das Missões, RS, Brasil \\ ${ }^{2}$ Docente, Departamento de Zootecnia e Ciências Biológicas, Universidade Federal de Santa Maria, Palmeira das Missões,
}

RS, Brasil

\begin{abstract}
Resumo
Este estudo teve o intuito de informar a população sobre plantas medicinais. Ao longo do trabalho ocorreram publicações em um jornal de notícia, distribuição de folheto informativo e divulgação de um vídeo com conteúdo elucidativo sobre a utilização de espécies medicinais. Foram aplicados questionários a 266 pessoas, que mencionaram 73 espécies medicinais, citando suas partes utilizadas e os referidos usos. Pode-se verificar com as perguntas realizadas aos acadêmicos entrevistados que a maioria deles utiliza as plantas medicinais somente em casos de doenças e seu conhecimento é oriundo dos familiares mais antigos.
\end{abstract}

Palavras-chave: Medicina popular. Fitoterapia. Etnobotânica.

\begin{abstract}
This study aimed to inform the public about medicinal plants. Throughout the work occurred publications in a news journal, leaflet distribution and dissemination of a video content with plain on the use of medicinal species. Questionnaires were administered to 266 people, who mentioned 73 medicinal species, citing its used parties and other uses. You can check with the questions asked to the academic interviewed that most of them use medicinal plants only in cases of diseases and their knowledge is coming from the oldest family.
\end{abstract}

Keywords: Folk medicine, phytotherapy, ethnobotany. 


\section{Introdução}

As plantas medicinais vêm sendo utilizadas para o tratamento, cura e prevenção de doenças desde a antiguidade, possuindo origem na China e Egito, difundindo-se, posteriormente, para outras regiões do mundo. O conhecimento dessas plantas simboliza recurso terapêutico de muitas comunidades, tal como indica a cultura transmitida dentro das civilizações.

No Brasil, as plantas medicinais da flora nativa são consumidas com pouca ou nenhuma comprovação de suas propriedades farmacológicas, propagadas por usuários ou comerciantes. Muitas vezes essas plantas são, inclusive, empregadas para fins medicinais diferentes daqueles utilizados pelos silvícolas. Comparada com a dos medicamentos usados nos tratamentos convencionais, a toxicidade de plantas medicinais e fitoterápicos pode parecer trivial. No entanto, a toxicidade de plantas medicinais é um problema sério de saúde pública. Os efeitos adversos dos fitomedicamentos, possíveis adulterações e toxidez, bem como a ação sinérgica (interação com outras drogas) ocorrem comumente (JUNIOR et al., 2005).

O estudo das plantas para fins terapêuticos está inserido em um contexto social e ecológico, sendo de grande importância para a população que sofre pressões econômicas e sociais, representando uma alternativa complementar aos tratamentos da medicina oficial. As pesquisas podem contribuir para a inserção de drogas seguras e eficazes na comunidade no combate de diversas patologias. Com base no uso e conhecimento popular, o importante crescimento mundial da fitoterapia dentro de programas preventivos e curativos tem estimulado a avaliação da atividade de diferentes extratos de plantas (BUFFON et al., 2001). Atualmente, o estudo das plantas medicinais, sob diferentes abordagens, priorizando inclusive a interdisciplinaridade como tratada por Di Stasi (1995), tem merecido especial atenção por parte de estudiosos preocupados com o conhecimento das potencialidades e riquezas vegetais (NETO, 2006).

Cada vez mais se tem observado os usos populares das plantas medicinais, enaltecendo a cultura das regiões e o conhecimento que continua sendo transmitido dentro das gerações. Nos últimos anos, inclusive, graças aos progressos alcançados nos métodos analíticos, os conhecimentos sobre as plantas com características terapêuticas aumentaram (FOGLIO et al., 2006). Contudo, ainda falta divulgar esses avanços à população, tal como informações adequadas sobre as propriedades das plantas medicinais, o alerta sobre o seu consumo concomitante com os medicamentos alopáticos sem aviso ao médico e a existência de plantas que apresentam toxicidade. Esse conjunto de fatores demonstra a necessidade de projetos que busquem informar a população sobre o uso correto das plantas medicinais.

Este é um trabalho desenvolvido no ano de 2014, durante o mês de julho até o mês de dezembro, cuja finalidade foi promover a divulgação de plantas medicinais através de meios de comunicação, como jornal e folhetos impressos. Além disso, buscou-se analisar o conhecimento que o meio acadêmico possui sobre espécies medicinais, tais como seus usos, frequência de utilização, entre outros.

\section{Metodologia}

O estudo iniciou-se com a escolha das plantas a serem divulgadas. Essa se deu através do artigo intitulado "Plantas medicinais utilizadas no município de Palmeira das Missões, RS, Brasil", de Battisti et al. (2013), com o qual foi possível verificar as plantas mais utilizadas no município e ver quais destas estão regulamentadas pela Agência Nacional de Vigilância Sanitária (ANVISA), Resolução no 10, de 9 de março de 2010. Ao final dessa análise, foram selecionadas 29 plantas.

Foi realizada uma pesquisa bibliográfica de cada planta selecionada e, posteriormente, textos informativos começaram a ser produzidos. Entrando em contato com o jornal Expressão Regional, Palmeira das Missões, RS, foi permitida a publicação semanal desses textos durante o segundo semestre de 2014. 
Com o auxílio da pesquisa foi também possível produzir um vídeo de plantas medicinais que ficou sendo transmitido no hall do prédio principal da UFSM - Campus Palmeira das Missões, no período de novembro a dezembro de 2014, sendo aplicados questionários (Figura 1) aos acadêmicos. Todos os cursos do Campus foram entrevistados: Administração, Ciências Biológicas - Licenciatura Plena, Ciências Econômicas, Enfermagem, Nutrição e Zootecnia. Após os questionários, os acadêmicos receberam um folheto impresso contendo informações sobre a utilização de plantas medicinais, que foi confeccionado no desenvolver do projeto.

Foi desenvolvida uma cartilha com breves resumos sobre as 29 plantas medicinais selecionadas no início da execução do projeto e com as formas de uso dessas espécies vegetais. Essa cartilha foi distribuída em meio acadêmico juntamente com um folder - também produzido durante o projeto contendo as plantas medicinais mais conhecidas e as formas de preparo.

\section{Resultados e Discussão}

As publicações no jornal, em 2014, ocorreram no período entre 18 de julho a 5 de dezembro, e foram referentes às seguintes plantas: alcachofra - Cynara scolymus L., espinheira santa - Maytenus ilicifolia (Scharad.) Planch., cidreira - Cymbopogon citratus (DC.) Stapf, jurubeba - Solanum paniculatum L., chapéu-de-couro - Echinodorus macrophyllus (Kunth) Mitcheli, tansagem - Plantago major L. , guaco - Mikania glomerata Spreng., calêndula - Calendula officinalis L., erva doce - Pimpinella anisum L., romã Punica granatum L., alecrim - Rosmarinus officinalis L., boldo - Plectranthus barbatus Andrews, alho Allium sativum L., camomila - Matricaria recutita L., dente de leão - Taraxacum officinale F.H. Wigg., anis estrelado - Illicium verum Hook. f., mil folhas - Achillea millefolium L., malva - Malva parviflora L., melissa - Melissa officinalis L. e picão - Bidens pilosa L.

Também foi elaborado durante o projeto o folheto, que foi distribuído aos acadêmicos após a aplicação dos questionários e buscou informar as plantas eficazes no tratamento das enfermidades mais comuns e como deve ser feita a utilização de chás medicinais.

$\mathrm{O}$ vídeo exposto na universidade trouxe aos acadêmicos e funcionários esclarecimento sobre as formas de preparo das plantas medicinais. Além disso, apresentou algumas espécies vegetais que possuem atividade medicinal, mostrando também as contraindicações e os cuidados que precisam ser tomados na utilização.

Com relação ao questionário, foram entrevistadas 266 pessoas, sendo $75 \%$ do sexo feminino, $24 \%$ do sexo masculino e $1 \%$ que não informou. $23 \%$ dos acadêmicos eram do curso de Administração, $18 \%$ de Ciências Biológicas - Licenciatura Plena, 10\% de Ciências Econômicas, 21\% de Enfermagem, 14\% de Nutrição e $14 \%$ de Zootecnia, sendo em sua maioria de semestres iniciais.

Referente à frequência da utilização de plantas medicinais (Figura 2), mais de uma alternativa poderia ser marcada, sendo, portanto, contabilizada a quantidade de citações. "Somente em casos de doenças" foi citada 124 vezes, seguindo de "Não utilizo" 46 vezes, "Diariamente" 36 vezes, "Na prevenção de doenças" 31 vezes e "Uso plantas e remédios sintéticos simultaneamente" 28 vezes. A respeito de como foi adquirido o conhecimento sobre as plantas medicinais mais de uma opção também poderia ser marcada, seguindo o mesmo modelo da primeira pergunta (Figura 3). A opção "Com meus familiares mais antigos" foi citada 224 vezes, sendo $67 \%$ do total. Com essa informação, verifica-se que o conhecimento popular transmitido de geração em geração continua prevalecendo, sendo importante para somar nas investigações sobre plantas medicinais. "Na internet" foi citada 31 vezes, "Lendo livros" 18 vezes, “Não tenho conhecimento" 14 vezes, "Na escola" 13 vezes, "Na faculdade" 12 vezes, “Na televisão/rádio" 11 vezes e "De outra forma” 10 vezes. 
UFSM - PROJETO PROLICEN -

Desenvolvendo e divulgando o conhecimento sobre plantas medicinais Data da aplicação ....................

Idade:

Curso:

\title{
IDENTIFICAÇÃO
} Semestre:

\author{
Sexo: ( ) Feminino ( ) Masculino
}

QUESTIONÁRIO

1. Com que frequência você utiliza as plantas medicinais?
( ) Diariamente
( ) Somente em casos de doenças
( ) Na prevenção de doenças
( ) Uso plantas e remédios sintéticos simultaneamente
( ) Não utilizo

2. Como você obteve o conhecimento sobre plantas medicinais?
( ) Na internet
( ) Na escola
( ) Na faculdade
( ) Lendo livros
( ) Com meus familiares mais
( ) Na televisão/rádio
( ) De outra forma antigos
( ) Não tenho conhecimento

3. Quais as plantas medicinais que você mais conhece? Para que elas servem? Quais partes você utiliza?

4. Você costuma usar algum tipo de planta no chimarrão? Que tipo? Para que serve?

5. Você utiliza dois ou mais tipos de plantas ao mesmo tempo para o tratamento de algum problema de saúde? ( ) Não ( ) Sim

Se sim, quais?

6. Você já teve reações inesperadas com a utilização de plantas medicinais?（）Não（） Sim

7. Você conhece alguma planta medicinal que pode ser tóxica?

( ) Não

( ) $\operatorname{Sim}$. Qual (is)?

$\mathrm{O}$ que provoca $(\mathrm{m})$ ?

Figura 1 - Questionário aplicado aos acadêmicos. 


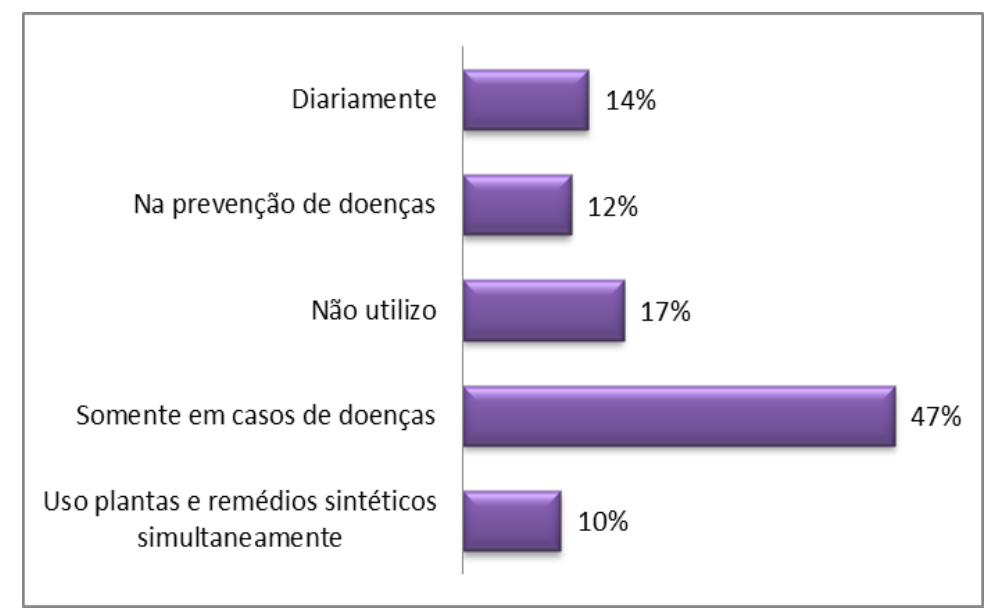

Figura 2 - Frequência da utilização de plantas medicinais.

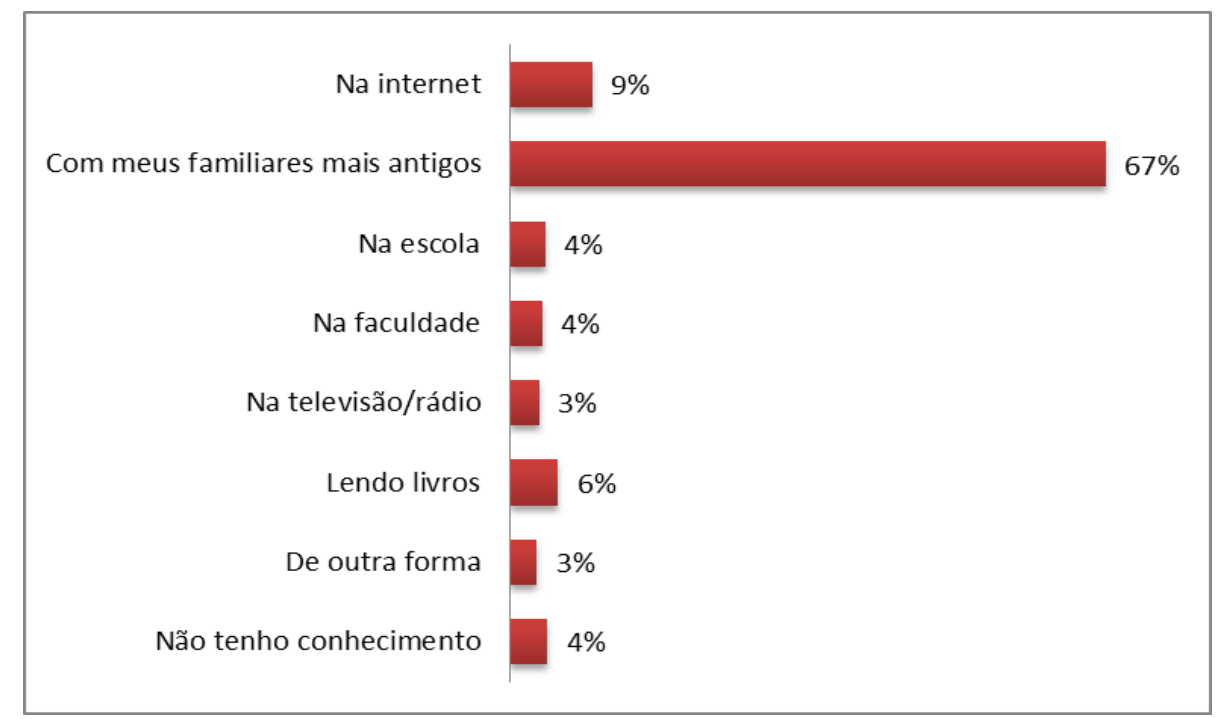

Figura 3 - Como foi adquirido o conhecimento sobre as plantas medicinais.

Quando questionados sobre quais plantas medicinais conheciam, os entrevistados, em um total, citaram 73 espécies medicinais, além de descreverem as partes utilizadas das plantas e para que essas servem (Tabela 1). Três acadêmicos mencionaram cogumelos como plantas medicinais e estes alegaram, na pergunta anterior, não possuírem conhecimento sobre plantas com propriedades terapêuticas. Para esclarecimento, cogumelos são fungos que possuem propriedades nutricionais e medicinais, além de toxicidade no caso de algumas espécies. A confusão dos acadêmicos deu-se, portanto, em citá-los como plantas. Algumas plantas foram mencionadas sem o referido uso, tais como: arruda, café, cannabis, cataflan, chapéu-de-couro, coentro, cogumelo, ginseng, manjericão, menstruz, novalgina, orégano e urtigão.

Com relação às partes utilizadas e para que servem as plantas medicinais, os acadêmicos demonstraram coerência, citando as partes e os fins medicinais corretos, salvo exceções. No caso da babosa foi mencionado que a planta é utilizada no tratamento de feridas internas, no entanto a sua indicação é para ferimentos externos, possuindo ação cicatrizante. Quando ingerida, é tóxica, devido à presença de antraquinonas. A hortelã foi citada como calmante; embora possua ação refrescante, é uma planta que eleva a pressão sanguínea. O boldo foi referido para dor de garganta, porém, de acordo com a literatura, é indicado no tratamento dos males do fígado e problemas da digestão.

Foi perguntado se algum tipo de planta medicinal era utilizado no chimarrão, onde $8 \%$ dos acadêmicos demonstraram não tomar chimarrão, $44 \%$ alegaram que não utilizavam nada no chimarrão, e $48 \%$ mencionaram fazer uso das plantas. A pergunta também buscava saber se os acadêmicos tinham o conhecimento da utilização medicinal de cada planta citada. 21 plantas foram 
Martins et al.: Desenvolvendo e divulgando o conhecimento sobre plantas medicinais

Tabela 1 - Espécies medicinais citadas pelos acadêmicos, seguido do no de citações, partes utilizadas e usos referidos

\begin{tabular}{|c|c|c|c|}
\hline Planta & $\begin{array}{l}\text { № de } \\
\text { citações }\end{array}$ & Parte da planta & Para que serve \\
\hline Abacate & 1 & Folhas (1) & Controle da pressão arterial (1) \\
\hline Agrião & 1 & & Aumenta a imunidade antigripal (1) \\
\hline Aipo & 1 & & Gripe (1) \\
\hline Alcachofra & 4 & Folha (1) & $\begin{array}{l}\text { Digestão (2) } \\
\text { Emagrecer (2) }\end{array}$ \\
\hline Alecrim & 6 & & $\begin{array}{l}\text { Dores e cólicas menstruais (1) } \\
\text { Tempero (1) }\end{array}$ \\
\hline Alho & 2 & & $\begin{array}{l}\text { Antibiótico e gripe (1) } \\
\text { Antioxidante (1) }\end{array}$ \\
\hline Ameixa & 1 & Folhas (1) & Gripe (1) \\
\hline Anis estrelado & 3 & Fruto (1) & $\begin{array}{l}\text { Cicatrizante (1) } \\
\text { Gripe (2) } \\
\text { Receitas (1) } \\
\end{array}$ \\
\hline Arnica & 1 & Folhas (1) & Machucados (1) \\
\hline Arruda & 2 & & \\
\hline Babosa & 31 & $\begin{array}{c}\text { Folhas (4) } \\
\text { Parte interna da } \\
\text { folha - liquido (7) }\end{array}$ & $\begin{array}{l}\text { Cicatrizante (13) } \\
\text { Infecções na pele (5) } \\
\text { Hidratação de cabelo (3) } \\
\text { Queimaduras (1) } \\
\text { Feridas internas (1) } \\
\text { Diminui o inchaço e dor de uma lesão (1) }\end{array}$ \\
\hline Bergamota & 6 & $\begin{array}{l}\text { Folhas (5) } \\
\text { Casca (1) } \\
\end{array}$ & $\begin{array}{l}\text { Gripe (3) } \\
\text { Dor de garganta (1) }\end{array}$ \\
\hline Boldo & 95 & Folhas (40) & $\begin{array}{l}\text { Má digestão (22) } \\
\text { Problemas estomacais (49) } \\
\text { Intestino (1) } \\
\text { Fígado (6) } \\
\text { Azia (1) } \\
\text { Dor de garganta (1) } \\
\end{array}$ \\
\hline $\begin{array}{l}\text { Cabelo-de- } \\
\text { milho }\end{array}$ & 1 & & Infecção urinária (1) \\
\hline Café & 1 & & \\
\hline Calêndula & 5 & Flores (1) & Antialérgico (1) \\
\hline Camomila & 88 & $\begin{array}{c}\text { Flores (18) } \\
\text { Toda a planta (2) } \\
\text { Sachê comprado (1) }\end{array}$ & $\begin{array}{l}\text { Calmante (44) } \\
\text { Problemas gástricos (1) } \\
\text { Dor de estômago (8) } \\
\text { Digestivo (3) } \\
\text { Antiinflamatório (2) } \\
\text { Bactericida (1) } \\
\text { Cólica (2) } \\
\text { Antialérgico (1) } \\
\text { Dormir (1) }\end{array}$ \\
\hline Cancorosa & 1 & Casca (1) & Colesterol (1) \\
\hline Canela & 6 & & $\begin{array}{l}\text { Atrasar a menstruação (1) } \\
\text { Cólicas menstruais (1) } \\
\text { Abortiva (1) }\end{array}$ \\
\hline
\end{tabular}

Tabela 1 -Continuação... 


\begin{tabular}{|c|c|c|c|}
\hline Planta & $\begin{array}{l}\text { № de } \\
\text { citações }\end{array}$ & Parte da planta & Para que serve \\
\hline Cannabis & 1 & & \\
\hline Carqueja & 6 & $\begin{array}{c}\text { Flor e caule (1) } \\
\text { Folha (1) }\end{array}$ & $\begin{array}{l}\text { Dor abdominal (1) } \\
\text { Emagrecer (1) } \\
\text { Estômago (2) }\end{array}$ \\
\hline Cataflan & 1 & & \\
\hline Cavalinha & 14 & Haste (3) & $\begin{array}{l}\text { Emagrecer (3) } \\
\text { Diurético (1) } \\
\text { Problemas urinários (3) }\end{array}$ \\
\hline Cebola & 1 & & Antibiótico e fonte de vitaminas (1) \\
\hline Chá mate & 1 & & Diurético (1) \\
\hline $\begin{array}{l}\text { Chapéu-de- } \\
\text { couro }\end{array}$ & 1 & & \\
\hline Chá verde & 15 & & $\begin{array}{l}\text { Emagrecer (5) } \\
\text { Acelera o metablismo (5) } \\
\text { Diurético (1) } \\
\text { Desintoxicante (2) } \\
\text { Envelhecimento precoce (1) } \\
\text { Digestão (1) }\end{array}$ \\
\hline Chuchu & 1 & Folhas (1) & Controle da pressão arterial (1) \\
\hline Cidreira & 44 & Folhas (16) & \begin{tabular}{|l} 
Calmante (14) \\
Pressão (4) \\
Problemas gástricos (1) \\
Digestão (2) \\
Dor de cabeça (1) \\
Gripe (1) \\
Febre (1) \\
Dormir (1) \\
Dor abdominal (1)
\end{tabular} \\
\hline Cidró & 6 & Folhas (2) & $\begin{array}{l}\text { Diurético (1) } \\
\text { Dormir (1) } \\
\text { Calmante (2) } \\
\text { Dor abdominal (1) } \\
\text { Antialérgico (1) }\end{array}$ \\
\hline Coentro & 1 & & \\
\hline Cogumelo & 3 & & \\
\hline Cravo & 1 & & Baixa pressão (1) \\
\hline Erva doce & 20 & Sementes (4) & $\begin{array}{l}\text { Calmante (7) } \\
\text { Má digestão (1) } \\
\text { Ativa o sistema imunológico (1) } \\
\end{array}$ \\
\hline $\begin{array}{l}\text { Espinheira } \\
\text { santa }\end{array}$ & 1 & Folhas (1) & $\begin{array}{l}\text { Problemas estomacais, do fígado e pressão alta } \\
\text { (1) }\end{array}$ \\
\hline Eucalipto & 1 & & Inalação (1) \\
\hline Fumeiro-bravo & 1 & & Dor de garganta (1) \\
\hline Funcho & 6 & Galhos (1) & $\begin{array}{l}\text { Bom funcionamento do intestino e aumentar o } \\
\text { leite (1) } \\
\text { Gases intestinais (1) }\end{array}$ \\
\hline
\end{tabular}


Tabela 1 -Continuação...

\begin{tabular}{|c|c|c|c|}
\hline Planta & $\begin{array}{c}\text { № de } \\
\text { citações }\end{array}$ & Parte da planta & Para que serve \\
\hline Gengibre & 23 & Raiz (1) & $\begin{array}{l}\text { Garganta (10) } \\
\text { Dor no estômago (3) } \\
\text { Cólica (1) } \\
\text { Aumenta a imunidade (1) } \\
\text { Antialérgico (1) } \\
\text { Antioxidante (1) } \\
\end{array}$ \\
\hline Ginseng & 1 & & \\
\hline Goiaba & 1 & Folhas (1) & Dor de barriga e diarreia (1) \\
\hline Guaco & 16 & Folhas (10) & \begin{tabular}{|l|} 
Gripe (11) \\
Tosse (1)
\end{tabular} \\
\hline Guaraná & 1 & & Energético (1) \\
\hline Hibisco & 5 & Flores (1) & \begin{tabular}{|l} 
Emagrecer (2) \\
Desintoxicante (1) \\
Digestão (1) \\
\end{tabular} \\
\hline Hortelã & 23 & $\begin{array}{l}\text { Folhas (3) } \\
\text { Ramos (1) }\end{array}$ & \begin{tabular}{|l|} 
Digestão (1) \\
Calmante (2) \\
Vários problemas (1) \\
Estômago (3) \\
Garganta (1) \\
\end{tabular} \\
\hline Laranja & 17 & $\begin{array}{l}\text { Casca (6) } \\
\text { Folhas (12) }\end{array}$ & \begin{tabular}{|l|} 
Gripe (14) \\
Fonte de vitamina C (1) \\
\end{tabular} \\
\hline Lima & 1 & Folhas (1) & Calmante (1) \\
\hline Limão & 3 & $\begin{array}{l}\text { Casca (1) } \\
\text { Folhas (1) }\end{array}$ & $\begin{array}{l}\text { Gripe (2) } \\
\text { Fonte de vitamina C e prevenção de gripe e } \\
\text { resfriados (1) } \\
\text { Diurético (1) }\end{array}$ \\
\hline Losna & 2 & Folhas (2) & $\begin{array}{l}\text { Sistema digestivo (1) } \\
\text { Cólica (1) } \\
\text { Estômago (1) } \\
\end{array}$ \\
\hline Malva & 17 & $\begin{array}{l}\text { Folhas (8) } \\
\text { Toda a planta (2) }\end{array}$ & $\begin{array}{l}\text { Bexiga (1) } \\
\text { Gargarejo garganta (1) } \\
\text { Infecção/inflamação bucal (10) } \\
\text { Dor (1) } \\
\end{array}$ \\
\hline Manjericão & 1 & & \\
\hline Manjerona & 6 & Folhas (4) & $\begin{array}{l}\text { Diurético (1) } \\
\text { Cólica }(2) \\
\text { Dor }(1) \\
\end{array}$ \\
\hline Maracujá & 1 & & Calmante (1) \\
\hline Marcela & 110 & $\begin{array}{l}\text { Flores (31) } \\
\text { Folhas (7) } \\
\text { Toda a planta, } \\
\text { exceto a raiz (4) }\end{array}$ & $\begin{array}{l}\text { Dores estomacais (56) } \\
\text { Digestão (14) } \\
\text { Dores intestinais (2) } \\
\text { Fígado (3) } \\
\text { Dores abdominais (3) } \\
\text { Gases (1) } \\
\text { Calmante (2) } \\
\text { Distúrbio inflamatório (1) } \\
\text { Dormir (1) }\end{array}$ \\
\hline
\end{tabular}


Tabela 1 -Continuação...

\begin{tabular}{|c|c|c|c|}
\hline Planta & $\begin{array}{l}\text { № de } \\
\text { citações }\end{array}$ & Parte da planta & Para que serve \\
\hline Melissa & 6 & & $\begin{array}{l}\text { Calmante (3) } \\
\text { Dores estomacais (1) }\end{array}$ \\
\hline Menstruz & 1 & & \\
\hline Novalgina & 1 & & \\
\hline Noz moscada & 1 & Pó (1) & Dor no estômago (1) \\
\hline Orégano & 1 & & \\
\hline Ortigão & 1 & Raiz (1) & \\
\hline Pata-de-vaca & 4 & Folhas (1) & Cálculos renais (1) \\
\hline Penicilina & 2 & & $\begin{array}{l}\text { Dor de garganta (1) } \\
\text { Infecção (1) }\end{array}$ \\
\hline Picão & 2 & Raiz (1) & Infecção urinária (1) \\
\hline Pitanga & 3 & Folhas (3) & \begin{tabular}{|l|} 
Diarreia $(2)$ \\
Dor de barriga (1) \\
\end{tabular} \\
\hline Poejo & 4 & $\begin{array}{l}\text { Folha e caule (1) } \\
\text { Folhas (1) }\end{array}$ & $\begin{array}{l}\text { Dor }(1) \\
\text { Gripe }(1) \\
\text { Cólica }(1) \\
\end{array}$ \\
\hline Ponto-alívio & 2 & Folhas (2) & $\begin{array}{l}\text { Expectorante e alivia sintomas de gripe (1) } \\
\text { Dor (1) }\end{array}$ \\
\hline Quebra-pedra & 6 & Folhas (1) & $\begin{array}{l}\text { Cálculos renais (1) } \\
\text { Para os rins (2) }\end{array}$ \\
\hline Salsa & 2 & $\begin{array}{c}\text { Sachê comprado (1) } \\
\text { Raiz (1) }\end{array}$ & Problemas nos rins e trato urinário (1) \\
\hline Sálvia & 4 & $\begin{array}{l}\text { Raiz (2) } \\
\text { Folhas (2) }\end{array}$ & \begin{tabular}{|l|} 
Rins $(2)$ \\
Para tosse e apetite (1) \\
\end{tabular} \\
\hline Sene & 3 & Folhas (1) & $\begin{array}{l}\text { Diurético (1) } \\
\text { Dores abdominais e funcionamento dos órgãos } \\
\text { internos (1) }\end{array}$ \\
\hline Tansagem & 7 & Folhas (1) & $\begin{array}{l}\text { Infecção (1) } \\
\text { Ação antiinflamatória (1) }\end{array}$ \\
\hline Tarumã & 1 & Casca (1) & Triglicerídeos (1) \\
\hline Valeriana & 1 & Sintético (1) & Ansiedade (1) \\
\hline
\end{tabular}

citadas, além de compostos industrializados e mistura de chás. As plantas mais utilizadas são: anis estrelado (10 citações) - hipertensor e utilizado para emagrecer; camomila (47 citações) - utilizada como calmante, cicatrizante, anti-inflamatório, para o estômago e melhorar o sabor do chimarrão; cidreira (16 citações) - é calmante e age contra problemas estomacais, sendo também utilizada no chimarrão para melhorar o sabor; erva doce ( 25 citações) - é calmante, melhora o sabor, possui ação antioxidante e contra cólicas e alergias; marcela (13 citações) - utilizada em problemas digestivos, intestinais e de dor de cabeça, além de ser calmante, ajuda no bem-estar e no melhor sabor do chimarrão. Chá verde e gengibre foram citados quatro vezes, hortelã foi citada três vezes, alecrim, canela e cidró foram citadas duas vezes, bergamota, cancorosa, nozes, cipó mil homens, funcho, laranja, melissa, noz moscada e sene foram citadas uma vez. Além destes, foi mencionado um composto de vários chás de farmácias de manipulação, utilizado para emagrecer, e um composto especial para chimarrão. Quanto à mistura referida acima, se trata de um chá feito com marcela, chá 
mate e camomila que, por sua vez, age como antioxidante e calmante, combatendo também problemas digestivos e reduzindo o colesterol.

Quando questionados sobre a utilização de mais plantas ao mesmo tempo no tratamento de algum problema de saúde, a maioria dos informantes forneceu respostas negativas, sendo $81 \%$ que não utilizam, $16 \%$ que utilizam e $3 \%$ que não responderam. $11 \%$ dos acadêmicos expressaram as misturas que fazem, e alguns até citaram para qual enfermidade é eficaz. Para gripe, foram citadas as seguintes plantas: funcho, poejo e guaco; poejo, limão e alecrim; limão/folha de laranja e guaco misturados com mel; cascas de laranja/bergamota com aipo; limão, folhas de bergamota e cascas de laranja; guaco, ponto-alívio e poejo; camomila e melissa, que são calmantes também; brotos de fumeiro bravo, folhas (sem talo) de bergamota e sálvia, que servem também para dor de garganta.

Acerca das reações inesperadas com a utilização das plantas medicinais verificou-se, novamente, a maioria das respostas sendo negativas, onde $93 \%$ dos acadêmicos disseram nunca ter reações adversas às procuradas com o uso das plantas. $3 \%$ dos entrevistados não informaram e $4 \%$ demonstraram já ter sofrido uma reação inesperada, onde sete desses acadêmicos responderam o que aconteceu. Dois acadêmicos demonstraram melhora do quadro clínico, enquanto os demais enfrentaram algum problema, seja ele por confusão da planta, excesso de chá ou motivo não informado. As reações citadas foram: problemas de diarreia, sonolência, tontura, espasmo, náuseas, vômitos, incontinência urinária, delírios, suador e tremedeira.

A última pergunta tinha como finalidade saber se os acadêmicos possuíam algum conhecimento sobre plantas medicinais que podem ser tóxicas. $88 \%$ dos entrevistados disseram não conhecer nenhuma planta medicinal que apresente toxicidade, $11 \%$ afirmaram conhecimento e os demais não informaram, compondo 1\%. Avelós foi a planta mais citada, possuindo cinco citações, onde os acadêmicos a associaram com a causa de náuseas, alergia, problemas no trato gástrico e mucosa. A babosa e comigo-ninguém-pode foram citadas três vezes, sendo provocadoras de alergia, ânsia de vômito e também queimaduras na pele, no caso da comigo-ninguém-pode. A mamona foi citada duas vezes, provocando aborto e falência dos órgãos. Também com duas citações esteve o confrei, ocasionando problemas no estômago. As demais plantas citadas e o que podem causar: arruda vômito e queimaduras na pele, erva-de-bicho - em feridas causa tétano, maconha - alucinações, alecrim - aborto, boldo - "um tipo é venenoso", alcachofra - estimula o sistema nervoso, e espirradeira, carqueja e absinto, ambas sem informação do que podem provocar.

\section{Conclusões}

O estudo conseguiu atingir um bom público, transmitindo as informações necessárias para a utilização correta de plantas medicinais. Os resultados obtidos com a aplicação dos questionários no meio acadêmico foram importantes para analisar o conhecimento popular. Muitas plantas foram citadas, além das tradicionais, e isso demonstra o quão rico é o conhecimento da população, que ainda segue passando o que sabe para as gerações, disseminando uma cultura que faz uso das plantas medicinais para a cura e prevenção de doenças.

Trabalhos como esse são essenciais para que mais estudos sejam realizados com a finalidade de se conhecer mais as propriedades terapêuticas das plantas. A maioria dos entrevistados afirmou usar as plantas medicinais em casos de doenças, o que torna necessário o esclarecimento sobre elas. Isso também é importante para que a prática medicinal com plantas continue sendo efetuada e transmitida através das gerações.

\section{Agradecimentos}

Os autores agradecem pela concessão de bolsa do Programa de Licenciaturas - PROLICEN da Universidade Federal de Santa Maria. 


\section{Referências}

BATTISTI, C. et al. Plantas medicinais utilizadas no município de Palmeira das Missões, RS, Brasil. Revista Brasileira de Biociências, v. 11, p. 338-348, 2013.

BUFFON, M. C. M. et al. Avaliação da eficácia dos extratos de Malva sylvestris, Calendula officinalis, Plantago major e Curcuma zedoarea no controle do crescimento das bactérias da placa dentária. Estudo "in vitro". Revista Visão Acadêmica. v. 2, n.1, p. 31-38, Janeiro/Junho, 2001.

FOGLIO, M. A. et al. Plantas medicinais como fonte de recursos terapêuticos: um modelo multidisciplinar. Construindo a história dos produtos naturais, 2006.

FORTES, R. C. \& NOVAES, M. R. C. G. Efeitos da suplementação dietética com cogumelos Agaricales e outros fungos medicinais na terapia contra o câncer. Revista Brasileira de Cancerologia, v. 52, n. 4, p. 363-71, 2006.

JUNIOR, V. F. V. et al. Plantas medicinais: cura segura. Química nova, v. 28, n. 3, p. 519-528, 2005.

LEÃO, R. B. A. et al. Levantamento de plantas de uso terapêutico no município de Santa Bárbara do Pará, Estado do Pará, Brasil. Revista Brasileira de Farmácia, v. 88, n. 1, p. 21-25, 2007.

LORENZI, H \& MATOS, F. J. A. Plantas medicinais no Brasil: nativas e exóticas cultivadas. Nova Odessa, SP: Instituto Plantarum, 2002.

MACIEL, M. A. M. et al. Plantas medicinais: a necessidade de estudos multidisciplinares. Química nova, v. 25, n. 3, p. 429-438, 2002.

NETO, G. G. O saber tradicional pantaneiro: as plantas medicinais e a educação ambiental. Revista Eletrônica do Mestrado em Educação Ambiental. v. 17, julho a dezembro, 2006. 